高分子論文集 (Kobunshi Ronbunshu), Vol. 44, No. 8, pp. 641-647 (Aug., 1987)

\title{
高分子反応によるポリプロパギルメタクリラートの簡便な合成と得られた ポリマーの光反応特性*
}

\author{
下川 努*1・西久保忠臣*1
}

(受付 1987 年1月17日・1987年3月14日)

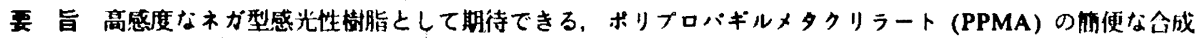
法として，プロバギルフロミドによるボリメタクリル酸のエステル化反応について検部した：この反応は，DMSO 中塩基として 1,8-ジアザビシクロ-[5.4.0]-ウンデセン-7 (DBU) を用いた場合，室温で約 10 分間以内に定量的に進 行することが判明した，得られた PPMA に看々の染据剂を机えてフィルム状態での光反応をIR-スベクトルの测 定により追跡するとともに, グレースケール法による相対感度の測定を行った，その結果、 PPMA は, 2-エチル (EAQ) あるいは2-メチルアントラキノン (MAQ), または、4モルホリノ-2,5-ジフトキシベンゼンジアソニウム

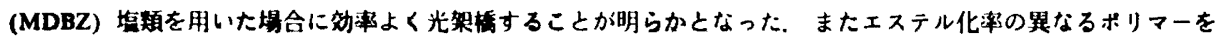

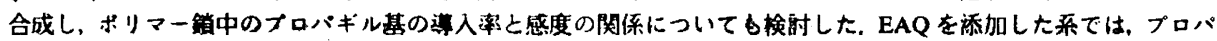

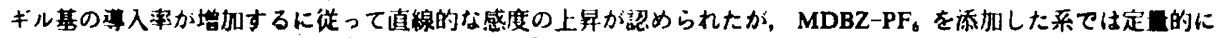
プパギル化した堨合にのみ光不溶化が起こった。
\end{abstract}

\section{1 籍言}

近年, 半導体集棈回路 (LSI) の高集皘化，高速化が急 速に進むなかで，その心滕部である回路パターンの形成 に必要なリングラフィー技術の発達には目ざましいもの がある.なかでも電子線や X 線を光䃇として用いるレ ジスト材には、サフミクロンの微細パターンを高精度に 描画できるものが多数報告”されている.

一方，古くから行われているUV 辉を利用するレジス 卜材の開発は，その解像力か限界とされる $1 \mu \mathrm{m}$ に達し てけるため, 主として感度，熱安定性，耐ドライエッチ ング性などの改善を目的とした研究が盛んに行われてい

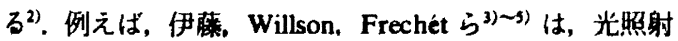
により極性が大きく変化する一連のポリマーの合成を行 い，得られたポリマーの感光特性について詳細な検討を

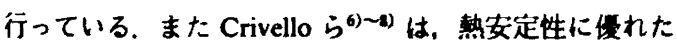
光カチオン重合開始剂であるジリルルードニウム塩や トリフェニルスルホニゥム塩類を用いた光硬化系につい て報告している。

しかしながら、レジスト材の合成という点に着目する と複雑な合成系路で不安定なモノマー合成を行わなくて はならない場合や、榐密な反応条件を設定しなければな

\footnotetext{
* 本研究を「感光性椒脂に関する研究 第 31 㫰」とする。

*1 神奈川大学工学部広用化学科 (-221 横浜市神奈川区六角棈 $3-27-1)$
}

らない場合が多かった．ここ数年著者らは，この問題点 に着目し，相間移動触媒法を用いた高分子反応による汎 用ポリマーの機能化の観点から，側鎖にシンナモイル 基9), ベンザルアセトフェノン基(10), 二トロアリール基(1) などを有する感光性樹脂を合成し，その感光特性，保存 安定性などについて検討を行ってきた，本研究では高感 度かつ熱安定性に優れた感光基としてプロバギル基に着 目し，側銷にこの構造を有するポリプロパギルメタクリ ラート (PPMA) の DBUを用いた簡使な合成法につい て検討するとともに, 得られた PPMA の感光特性など についても検討を行ったので㫰告する. (Scheme 1)

\section{実的}

\section{1 試薬及ひ溶媒}

メタクリル酸、プロパギルフロミト及び溶媒類はすべ て蒸留精彆したものを使用した. N.N'ーアソビスインフ チロニトリル (AIBN) は $50^{\circ} \mathrm{C}$ 以下でメタノールを用い て再結晶したものを用いた. 1,8-ジアザビシクロ-[5.4.0]ウンデセン-7 (DBU), 光架橋威であるベンソフェノン (BP), ミヒラーズケトン (MK), 4-(N,N-ジメチルアミ ノ)ベンソフェノン (ABP) 2-メチルアントラキノン (MAQ), 2-エチルアントラキノン (EAQ), ベンソイン イメプロピルエーテル (BIPE), 2,6-ビス (4'-アジドベン ザル)-4-メチルシクロヘキサノン (BABC)、4-モルホリ ノ-2,5-ジフトキシベンゼンジアゾニゥム塩類 (MDBZ), 4-(N,N-ジメチルアミノ) ベンゼンジアゾニゥム塩類 
下川・西久保

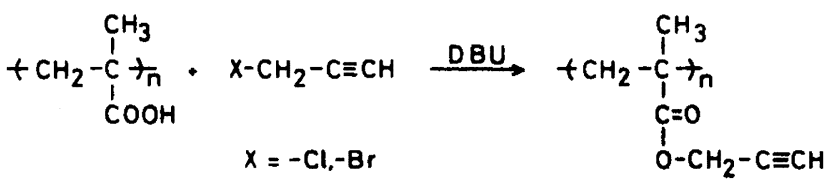

PPMA

Scheme 1.

Table 1. Condition and results of the reaction of PMA with PBa)

\begin{tabular}{clc}
\hline No. & Solvent & $\begin{array}{c}\text { Degree of } \\
\text { esterification (\%) }\end{array}$ \\
\hline 1 & DMSO & $0^{\text {b) }}$ \\
2 & DMF & 62.5 \\
3 & Methanol & 21.3 \\
4 & Water & 4.3 \\
5 & DMSO & 93.0 \\
\hline
\end{tabular}

- Reaction was carried out using 3 mmol of PMA with $3 \mathrm{mmol}$ of PB and $3 \mathrm{mmol}$ of DBU in $6 \mathrm{ml}$ of solvent at room temperature for 10 minutes. PMA, poly(methacrylic acid); PB, propagyl bromide; DMSO, dimethyl sulfoxide; DMF, dimethylformamide.

b) Reaction was carried out using $3 \mathrm{mmol}$ of potassium hydroxide and $0.3 \mathrm{mmol}$ of tetrabutylammonium bromide at $60^{\circ} \mathrm{C}$ for $24 \mathrm{~h}$.

(DMAZ), ジフェニルヨードニウムヘキサフルオロホス

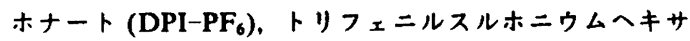
フルオロアンチモナート(TPS-SbF 6 ) は市販品をそのま ま使用した。 $4,4^{\prime}$-ジメルカプトジフェニルエーテル (DMDE) は既報(2)に従って合成した。

2.2 ポリプロパギルメタクリラート (PPMA) の合成 AIBN を開始剂とするラシ்カル重合により，エタノー ル中で合成したポリメタクリル酸 (PMA、還元粘度

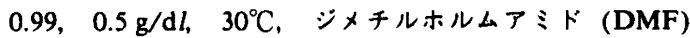
中), $17.22 \mathrm{~g}(0.2 \mathrm{~mol})$ を DMSO $400 \mathrm{ml}$ に溶解させた. 次にこの溶液に， $23.79 \mathrm{~g}(0.2 \mathrm{~mol})$ のプロパギルフロミ ト及び, $30.45 \mathrm{~g}(0.2 \mathrm{~mol})$ の DBU を加え，室温で 30 分 間かくはんした後，酢酸 $30 \mathrm{~m} /$ を加えてから大量の水を 注ぎ入れた。沈殷したボリマーをテトラヒドロフラン (THF)-水で 3 回, THF-メタノールで 1 回再沈精製し, $30^{\circ} \mathrm{C}$ で減任乾嬠した。収量 $22.09 \mathrm{~g}$, 這元粘度 $0.98 \mathrm{~d} / / \mathrm{g}$ $\left(0.5 \mathrm{~g} / \mathrm{d} l, 30^{\circ} \mathrm{C},(\mathrm{DMF})\right.$ 中) 中和滴定及び 'H NMR 上 り求めたポリマーのエステル化率は $99.6 \%$ 及ひ $100 \%$ であった.

IR (film): $3280 \mathrm{~cm}^{-1}$ ( $\left.\equiv \mathrm{C}-\mathrm{H}\right), \quad 2120 \mathrm{~cm}^{-1} \quad(\mathrm{C} \equiv \mathrm{C})$ $1730 \mathrm{~cm}^{-1}(\mathrm{C}=\mathrm{O})$
${ }^{1} \mathrm{H}$ NMR $\left(\mathrm{CDCl}_{3}\right.$, 内部標隼 TMS $)$ ： $\delta 0.82\left(-\mathrm{C}-\mathrm{CH}_{3}\right)$, $1.80\left(-\mathrm{CH}_{2}-\mathrm{C}-\right), \quad 3.50(-\mathrm{C} \equiv \mathrm{CH})$, and $4.61 \mathrm{ppm}(-\mathrm{O}$ $\mathrm{CH}_{2}$ )

\subsection{PPMA の光反応性}

PPMA $0.1 \mathrm{~g}\left(8.06 \times 10^{-4} \mathrm{~mol}\right)$ を THF 約 $3 \mathrm{ml}$ に溶解 させ、これに光架橋剤 $4.03 \times 10^{-5} \mathrm{~mol}$ (PPMA に対して $5 \mathrm{~mol} \%$ ) を加えた溶液を $\mathrm{KBr}$ 板に枚布し，室温で 1 時 間減圧乾燥して厚さ約 $2 \mu \mathrm{m}$ のフィルムを調製した。 こ のフィルムに $250 \mathrm{~W}$ 超高圧水銀灯（ウシオ電気(株) 製 USH-250 D) を $30 \mathrm{~cm}$ の距離から照射し，IR-スベクトル (日本分光(株) 憋, A-202 型) で $3280 \mathrm{~cm}^{-1}$ の三重結合性 炭素-水菜結合の淢少速度を測定した。

\subsection{PPMA の相対煘度测定}

PPMA $0.1 \mathrm{~g}$ を $4 \mathrm{ml}$ のアニソールに溶解させてから光 架橋風を PPMA に対して $5 \mathrm{~mol} \%$ 添加した溶液を銅板 に均一に染布し，室温で 1 時間減圧乾燥させた後, Kodak Step Tablet No. 2 (Eastman Kodak 社製) を重杍 てケミカルランプ (八千代スチール器材(株) 製ミニプリ ンターB4）で $3 \mathrm{~cm}$ の距離から蕗光し，アセトンで 2 分 間現像を行い不溶化段数を求めた.

\section{3 耛果及ひ考察}

\subsection{PPMA の合成}

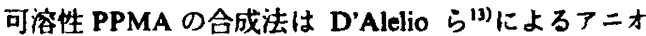
ン重合を用いた例がある他，ラジカル重合による合成法

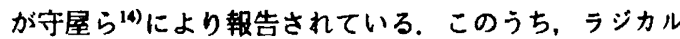
重合を用いた場合は，ポリマーの収率が高くなるとゲル 状物が生成することる報告されている，しかしながら， ポリメタクリル酸の高分子反応による PPMA の合成は， 著者らの知るかきり報告されていない，そこで種々の溶 媒中，壏基として DBU を用いてこの反応を行い，その 結果を Table 1 に示した. DMSO 中でこの反応は10分 間で 93\%とほぼ定量的に進行した. PMA の DMSO 中 でのエステル化速度をプロパギルブロミド (PB) とクロ リド (PC) を用いて测定し、結果を Fig. 1 に示した. PMA のエステル化は PB を用いた場合の方が PC を用 いた場合よりも著しく速く進行した.このことは，反応 が $S_{N 2}$ 的に進行するためであると推定される。ささらに, DBU を用いた場合上訅のように反応が速やかに進行す るのは，DBU が極めて強い塩基であるにもかかわらず, 
反応中間体として生成する PMA の DBU 塩が DMSO に可管であるため反応を均一系で行えること，また反応 基質である PB の3位の炭菜がプロム基及びエチニル基 の二つの電子吸引性基により活性化されていることなど の理由によるものと考えられる. 以上のことから PMA のポリマー側鎖に，定量的にプロパギルエステル基を導 入するためには，PMA と PB とを DBU 存在下 DMSO 中室温で 30 分間程度反応させればよいということが明 らかとなったこのことは DMSO-DBU-PB系がカルボ ン酸の優れたエステル化試薬として作用することを指示

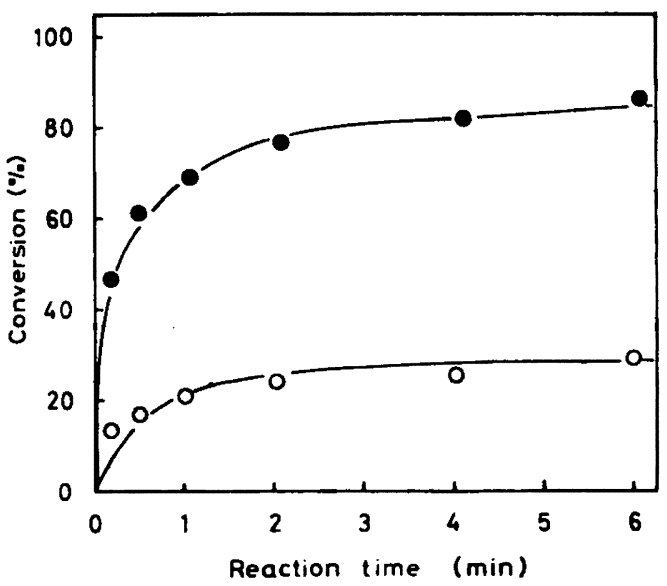

Fig. 1. Rates of esterification of poly (methacrylic acid) by propargyl halide using DBU in DMSO at room temerature. $\mathrm{PB}$; $\mathrm{O}, \mathrm{PC}$.
している.この系で得られた PPMAのIR-スペクトル及 び'H NMR スペクトルを Fig. 2, 3 にそれぞれ示した. さらに上記の反応で得られた PPMA は，室温で数か月 間放置しても架橋せず，侵れた保存安定性を有している ことも判明した。

\subsection{PPMA の光反応}

Hay ${ }^{15) .16)}$ 及び加藤ら ${ }^{17)}$ はそれぞれポリマー主鎖及び 側鎖にプロパギル基を有するポリマーの合成とその光架 橋反応について検討し、プロパギル基が優れた感光基で あること及びベンソフェノンやヘンソインなどの增感剤 の添加により光架橋反応が促進されることを報告してい ろ.しかしながら、ペロパギル基は他に光カチオン重合, 光マイケル付加反応及び芳香族ビスアジド化合物との付 加反伈などの光架槅反吣が期待できる官能基であるが, これらのことについてはいずれも検討されていない，そ こで種々の光架橋剂を加えた PPMA の光架橋反応につ いて検討を行った，まず既報を参考として，種々の光增 感剂を $5 \mathrm{~mol} \%$ 添加したフィルムに $250 \mathrm{~W}$ 超高圧水銀 奵を $30 \mathrm{~cm}$ の距離から照射し IR-スペクトルで 3280 $\mathrm{cm}^{-1}$ の三重結合性メチン (三C-H) の吸収の減少速度を 測定した結果を Fig. 4 に示した. PPMA の光反応速度 は，MAQを用いた場合最も速く，次いで EAQ, MK, BIPE，BP の䐓に低下していくことが明らかとなった。 光照射後の PPMA のIR-スペクトルは，どの增感剤を用 いた場合でも $3280 \mathrm{~cm}^{-1}$ の三重結合性メチンの吸収ピー クの減少以外にも，3000 2900 $\mathrm{cm}^{-1}$ 付近の炭素水菜結 合及び $2140 \mathrm{~cm}^{-1}$ の三重結合のピークの若干の減少が認 められた。 また新たに $3600 \mathrm{~cm}^{-1}$ に水酸基に基づく吸収

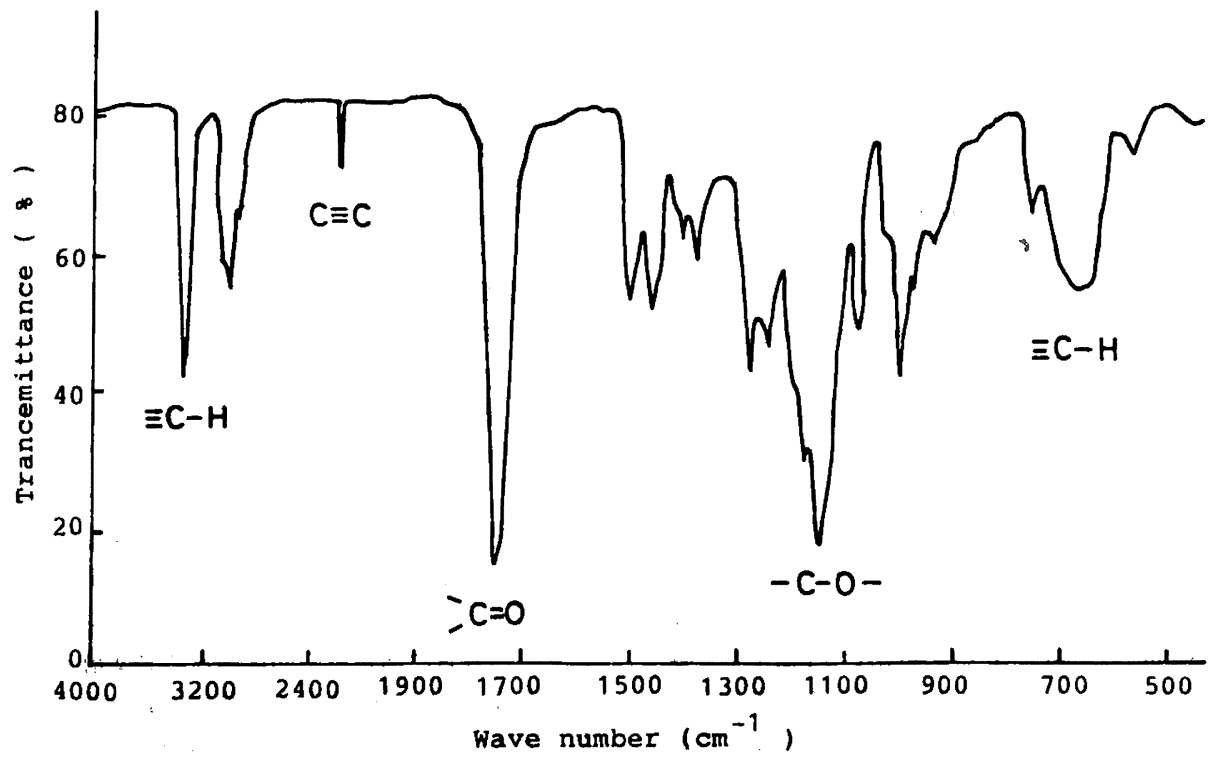

Fig. 2. IR spectrum of PPMA. 


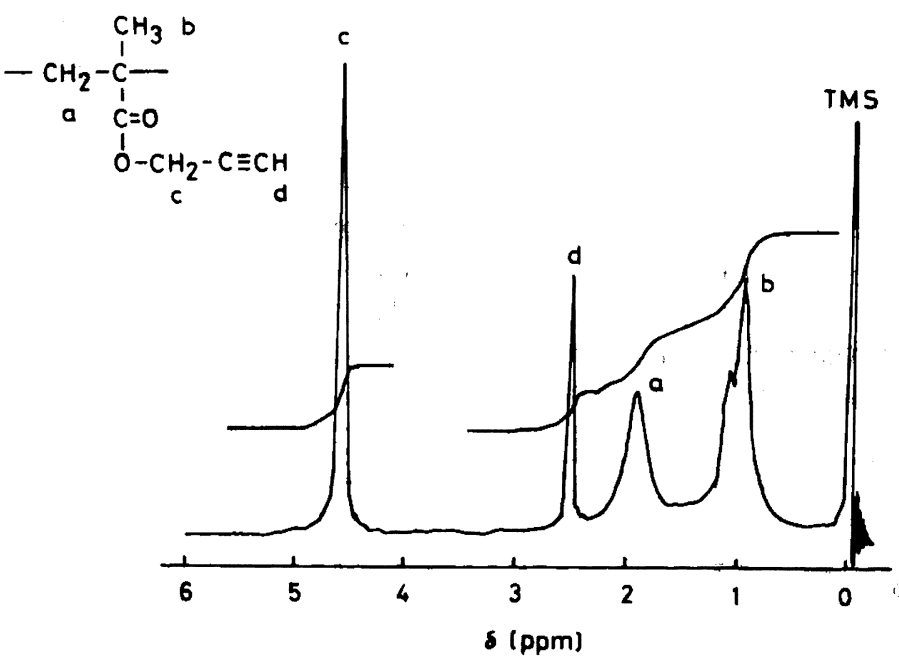

Fig. 3. ${ }^{1} \mathrm{H}$ NMR spectrum of PPMA.

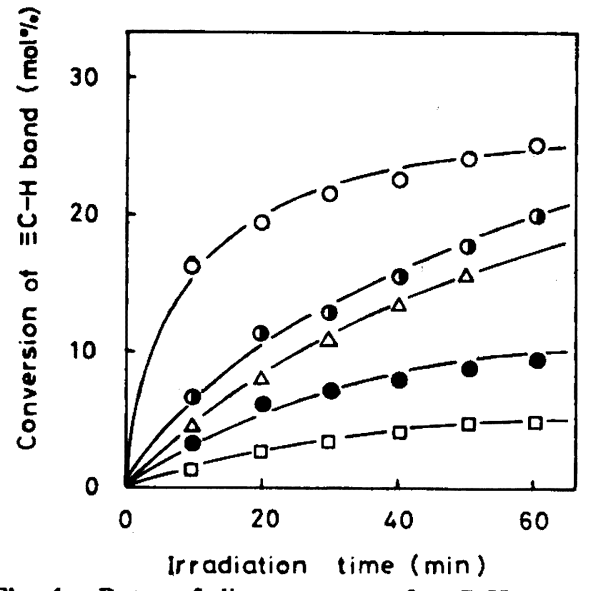

Fig. 4. Rates of disappearance of $\equiv \mathbf{C}-\mathbf{H}$ bond of PPMA with various photosensitizers: (O), MAQ; (O), EAQ; $(\triangle), \mathrm{MK}$; (О), BIPE; ( $\square)$, BP.

が現れた.これらのことから，PPMAの光架橋は主とし て增感剂による水素引き抜き反応により生じた，プロパ ギルラジカルの三重結合への付加おるいはラジカルどう しのカップリングにより進行すると考えられるが, これ らの反灾の他にも三重結合の単独重合 ${ }^{17)}$ や酸素によるプ ロパギル基の酸化反応など(8)が一部関与していることも 考えられる。

次に PPMA の種々の有機溶媒に対する溶解度試験を 行い結果を Table 2 に示した。 この表から PPMA は, ん゙ ンゼン, トルエン, キシレンなどの芳香族炭化水菜系の 溶媒には膨潤するのみであるが、アセトン, MEK, 酢酸 エチル、ジオキサンなどの汎用溶媒には可溶であること
Table 2. Solubility of PPMA*)

\begin{tabular}{lcc}
\hline \multicolumn{1}{c}{ Solvent } & \\
\hline Benzene & \pm & \pm \\
Toluene & ++ \\
Xylene & ++ \\
Chloroform & ++ \\
Acetone & ++ \\
THF & ++ \\
MEK & - \\
Ethylacetate & - \\
Isopropanol & ++ \\
Methanol & ++ \\
Dioxane & ++ \\
Diglyme & ++ \\
Anisol & \pm \\
Methoxyethanol & \pm \\
Chlorobenzene & ++ \\
Methylchloroform & - \\
1,2-Dichloroethane & $n$-Hexane & + \\
\hline
\end{tabular}

a) THF, tetrahydroforan; MEK, methyl ethyl ketone. ++ , soluble at room temperature; \pm , swelling; - , insoluble.

が判明した。これらの知見をもとに，PPMAの相対感度 測定には， PPMA フィルムのキャスト溶媒としてアニ ソールを，また現像溶媒としてアセトンをそれぞれ選択 した.これらの溶媒を用い，種々の光架橋剂を添加して 行った PPMA の相対感度测定の結果を Table 3 に示し た. 前述の光反応速度の測定に用いた光增感剂を添加し た系では，光反応速度の速い增感凨はど高い感度を示す 
高分子反応によるポリプロパギルメタクリラートの籍便な合成と得られたポリマーの光反応特性

Table 3. Practical photosensitivity of PPMA with various photosensitizers and photo-generated cationic catalysts (PGCC)"

\begin{tabular}{rlr}
\hline No. & $\begin{array}{c}\text { Photosensitizer } \\
\text { or PGCC }\end{array}$ & Insoluble step ${ }^{\text {b) }}$ \\
\hline 1 & MAQ & 8 \\
2 & EAQ & 6 \\
3 & MK & 5 \\
4 & BIPE & 0 \\
5 & BP & 0 \\
6 & DMDE-EAQ & - \\
7 & BABC & - \\
8 & MDBZ-SbF & 16 \\
9 & MDBZ-PF & 16 \\
10 & MDBZ-BF $_{4}$ & 16 \\
11 & DMAZ-SbF $_{6}$ & 0 \\
12 & DMAZ-PF $_{6}$ & 0 \\
13 & DMAZ-BF $_{4}$ & 0 \\
14 & DPI-PF $_{6}$ & 0 \\
15 & TPS-SbF $_{6}$ & 5 \\
\hline
\end{tabular}

a) MAQ, 2-methylanthraquinone; EAQ, 2-ethylanthraquinone; MK, Michler's ketone; BIPE, benzoine isopropylether; DMDE, 4,4'-dimercaptodiphenylether; BABC, 2,6-bis (4' -azidobenzal)- 4 -methylcyclohexanone; MDBZ, 4-morpholino-2,5-dibutoxybenzenediazonium; DMAZ, 4-(N,N-dimethylamino)benzenediazonium; DPI, diphenyliodonium; TPS, triphenylsulfonium.

") Step number.

という傾向が認められた（No. 1〜5). また，多官能性了 リルオリコマーの光架橋によく用いられるジチオールと 增感戍とから成る DMDE-EAQ 系 ${ }^{19)}$ (No. 6) 及び懪化 コムの架橋郕として有名な BABCを添加した系 (No. 7) では，共に光照射前にポリマーがゲル化し，感度測定に はいたらかったこの原因はおそらく前者の場合には千 オール基とプロパギル基との熱的なマイケル付加反応 が、また後者の場合にはアシト基とプロパギル基との 1,3-双極子環化付加反沈年がそれぞれ起きたためである と思われる。ささらに光カチオン重合開始触媒である MDBZ 塩類を用いた場合 (No. 8 10), PPMA は使用し た光架橋戍中最高の感度を示した。 D'Alelio ら ${ }^{(3)}$ はプロ パギルメタクリラートの塩化アルミニウムを用いたかチ オン重合により不溶性のポリマーが得られることを，東 村ら ${ }^{21) .223}$ は六塩化タッグステンなどのハロゲン化金属 錯体により置換アセチレン類が容易に重合することをそ れぞれ報告している。これらのことから，光カチオン重 合開始触某を添加した系では PPMA 側鎖のプロパギル 基がカチオン重合を起こすことにより架橋が進行してい

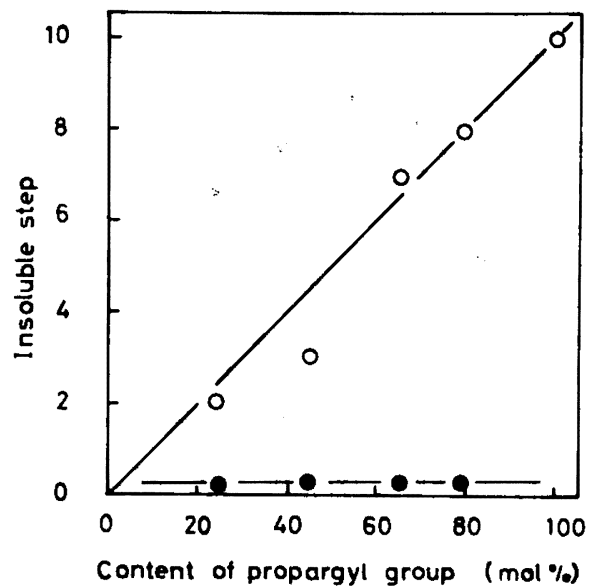

Fig. 5. Effect of propargyl content of practical photosensitivity of PPMA: O, EAQ/5 minutes irradiation;,$M D B Z-P_{d} / 5$ minutes irradiation.

るのではないかと思われる．この仮定を裏つけるため に，前述の增感戍類を用いて行ったのと同様の条件で MDBZ-PF 6 を含むPPMAのフィルムに光照射を行い, その IR-スペクトルを測定したところ， $3280 \mathrm{~cm}^{-1}$ の三 重結合性メチンの吸収ピークの隇少か認められた。この ことは，PPMA 側鎖のプロパギル基がカチオン重合によ り架橋するという仮定を支持しているものと考えられ ろ.一方，DMAZ 塩類を用いた系 (No. 11〜13) では, PPMA の光不溶化は観察されなかった。これは，おそら く、いずれの DMAZ 塩類もアニンールに極めて溶解性 が悪いため均一な感光性フィルムを得られないためと思 われる. さらに, Crivello ら 23),24kより芳香族ビスプロ ペニルエーテル類やエポキシ化合物の光重合に効果のあ ることが報告されている TPS-SbF た場合 (No. 14 15) には，PPMA の不溶化段数はそれ ぞれ 5 及び0段であった。このことは本研究で使用した 光照射装置が TPS 塩や DPI 塩の最大吸収波長である $230 \mathrm{~nm}$ 及び $227 \mathrm{~nm}$ 付近の光をほとんど発生しないため であると思われる，以上のことから，PPMAの光架橋戍 としてはアントラキノン系の增感剂及び MDBZ 系の光 カチオン重合開始触媒が侵れていることが明らかとなっ た.

次に，ポリマー側鎖の感光基の算入率がその感度にど のような影響を与えるかを調へるため，種々のエステル 化率を有するポリマーを合成し，EAQ と MDBZ-PF を架橋剂に用いて, グレースケール法による相対感度の 測定を行いその結果を Fig. 5 に示した。興味深いこと に，EAQを添加した系では，プロパギル基の導入率と感 度との間に直線関係が認められた。しかしながら， MDBZ-PF 6 を添加した系では，定量的にエステル化し 
下川・西久保

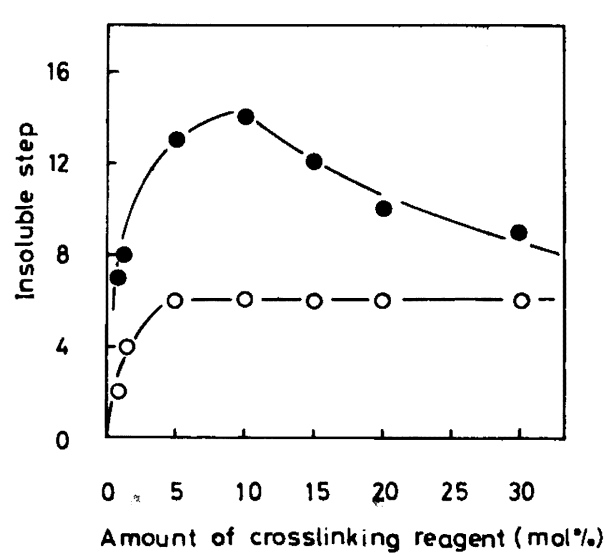

Fig. 6. Effect of crosslinking reagent concentration of practical photosensitivity of PPMA: O, MDBZ$P F / 1$ minute irradiation; $O, E A Q / 3$ minutes irradiation.

たポリマー以外には光不溶化は起こらなかった.このこ とは，ポリマー側銷のカルボキシル基あるいはその近傍 に吸着した水分子がプロパギル基のカチオン重合を阻害 するためであろうと推定される．最後に100\%プロパギ ル化した PPMA を用いて, EAQ 及び MDBZ-PF 6 の添 加量と感度との関係を Fig. 6 に示した. $\mathrm{MDBZ}^{-\mathrm{PF}_{6}}$ 添加した系では，PPMA に対して約 $10 \mathrm{~mol} \%$ の添加量 のところに極大値が現れ，それ以上の $\mathrm{MDBZ}-\mathrm{PF}_{6}$ の添 加は感度の低下をもたらした。このような感度の低下 は，MDBZ-PF6 によるフィルター効果であると考えら れる. 一方 EAQを添加した系では，PPMAに対して約 $5 \mathrm{~mol} \%$ の添加量のところで感度の飽和現象か観察され た.このような感度の跑和は、 EAQを含むPPMA フィ ルムが光照射により暗褐色に着色するために起こるもの と考えられる. 以上のことから，PPMAに対する光架橋 剂の添加量は MDBZ 塩類を用いる場合にはPPMA に対

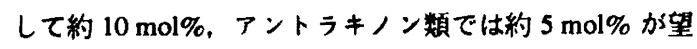
ましいということか明らかになった。

\section{4 桔論}

PMA とPB との反応による PPMA の合成について検 討した，この反応は，DMSO中，塩基として DBUを用 いることにより，室温で容易かつ定量的に進行すること が明らかとなった。得られた PPMA 侵れた保存安定性 を有しており，增感剤おるいは光カチオン重合開始触媒 である MDBZ 塩類を添加して光照射することにより効 率よく架橋し高い感度を示した。ささらに PMA 側鎖の力 ルボキシル基を部分的にプロパギル化したポリマーを合 成し，相対感度を測定したところ，EAQを添加した系で は感度とポリマー中の感光基搌度との間に直線関係が現
れたか、MDBZ-PF。 を添加した系では定量的にプロパ ギル化したポリマー以外は架橋不溶化しないことが分

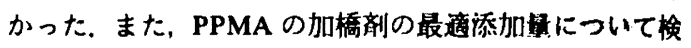
討したところ，EAQ は PPMA に対して $5 \mathrm{~mol} \%$, MDBZ-PF 6 では $10 \mathrm{~mol} \%$ という値であった。

$$
\text { 文载 }
$$

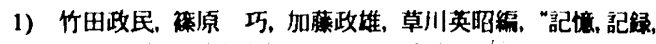
感光材料”，学会出版センター, 東京 (1985), p. 13〜26.

2) 例えは， C. G. Willson, H. Ito, J. M. J. Frechet, T. G. Tessier, and F. M. Houlihan, J. Electrochem. Soc., 133, 181 (1986).

3) H. Ito and C.G. Willson, "Polymers in Electronics", T. Gavidson Ed., ACS Symposium Series, 242, Washington, D. C. (1984), p. 11.

4) J. M. J. Fróchet, T. C. Tessier, C. G. Willson, and H. Ito, Macromolecules, 18, 317 (1985).

5) H. Ito, C. G. Willson, and J. M. J. Fróchet, U. S. Patent 4,491,628 (1985).

6) J. V. Crivello and J. H. W. Lam, J. Polym. Sci., Polym. Symp. No. 56, 383 (1976).

7) J. V. Crivello and J. H. W. Lam, J. Rad. Curing, July 2 (1977).

8) J. V. Crivello and J. H. W. Lam, Macnomolecules, 10, 1307 (1977).

9）西久保忠臣、高橋栄治、饭沢孝司、長谷川正木，日本化学 会誌, 306 (1984).

10）即讯孝司, 西久保忠臣、種市 宏, 長谷川正木, 日本化学 会誌, 2071 (1984).

11) 内田二郎、高模栄治, 飯沢孝司, 西久保忠臣, 日本化学会 誌, 65 (1986).

12) C. S. Marvel and P. D. Caeser, J. Am. Chem. Soc., 73, 1079 (1951).

13) G. F. D'Alelio and C. Evers, J. Polym. Sci, A-1, 5, 999 (1976).

14）守屋雅文，野間志郎，山下忠学，高分子化学，28，152 (1971).

15) A. S. Hay, D. A. Bolon, K. R. Leimen, and R. F. Clark, J. Polym. Sci., Polym. Lett, Ed., 8, 97 (1970).

16) A. S. Hay, D. A. Bolon, and K. R Leimer, J. Polym. Sci., A-I, 8, 1022 (1970).

17) 加藤政雄，米重康生，高分子編文集，37，243 (1980).

18) I. Haller and G. C. Pimentel, J. Am. Chem. Soc., 84, 2855 (1962).

19) C. R. Morgan, F. M. Mongotta, and A. D. Ketley, J. Polym. Sci. Polym. Chem. Ed., 15, 627 (1977).

20) R. Huisgen, C. Szeimies, and L. Möbius, Chem. Ber., 100, 2494 (1967).

21) T. Higashimura, Y.-X. Deng, and T. Masuda, Macromolecules, 15, 234 (1982).

22) T. Masuda, T. Takahashi, and T. Higashimura, Macromolecules, 18, 311 (1985).

23) J. V. Crivello, J. H. W. Lam, J. E. Moore, and S. H. Schroeter, J. Rad. Curing, 5, 2 (1978).

24) J. V. Crivello and D. A. Conlon, J. Polym. Sci. Polym. Chem. Ed., 22, 2105 (1984). 
高分子反応によるポリプロパギルメタクリラートの簡便な合成と得られたポリマーの光反応特性

Convenient Synthesis of Polymer Containing Pendant Propargyl Groups and Photochemical Properties of the Resulting Polymer*

Tsutomu ShimoKaWA ${ }^{1 *}$ and Tadatomi NishikUBo'*

*Studies on Photosensitive Polymer. XXXI.

*' Department of Applied Chemistry, Faculty of Engineering, Kanagawa University (27-1, Rokkakubashi, Kanagawa-ku, Yokohama, 221, Japan)

Poly(propargyl methacrylate) was synthesized by the reaction of poly(methacrylic acid) and propargyl bromide using DBU in DMSO. The reaction proceeded quantitatively at room temperature within 10 minutes. Photochemical properties of the resulting polymer were measured by IR spectroscopy and practical photosensitivitiy with several photosensitizers or photogenerated cationic catalysts as crosslinking reagents. The polymer showed the highest photosensitivity when 2-alkylanthraquinone or 4-morpholino-2,5-dibutoxybenzenediazonium salts were used as crosslinking reagents.

KEY WORDS Poly(propargyl methacrylate) / Poly(methacrylic acid) / DBU / Propargyl bromide / Photochemical Reaction / Practical Photosensitivity /

(Received January 17, 1987: Accepted March 14, 1987)

[Kobunshi Ronbunshu, 44 (8), 641-647 (1987)] 